\title{
Multi-inquiry hybrid e-learning: Instructor-learner experiences
}

\author{
Valerie Oji1 ${ }^{1}$ Katherine Dillion², Salome Weaver ${ }^{3}$ (I) \\ 1 Department of Clinical Medicine, New York Institute of Technology College of Osteopathic Medicine, Jonesboro, Arkansas, United States \\ ${ }^{2}$ Center for Teaching and Learning, Harding University, Searcy, Arkansas, United States \\ 3 Department of Clinical and Administrative Pharmacy Sciences, Howard University College of Pharmacy, Washington DC, United States
}

\author{
Keywords \\ Hybrid e-learning \\ Professionalism \\ Qualitative assessment \\ Teaching-learning method
}

\section{Correspondence}

Valerie Oji

Department of Clinical Medicine New York Institute of Technology College of Osteopathic Medicine Jonesboro

Arkansas 72401

United States

voji@nyit.edu

\begin{abstract}
Background: Hybrid teaching methodologies involve the purposeful combination of traditional teaching with technology advances. Despite some challenges, they have gained popularity recently, especially during the coronavirus pandemic. This study evaluated hybrid e-learning with multiple inquiries involving students' receptiveness, preferences, behaviours and instructor observations. Method: The methodology involved a mixed-method approach with a qualitative observational case study, surveys and interviews for problembased learning alternatives to traditional lectures. Instruction included: 1) Assigned primary literature reading with study questions to be completed before class; 2) Out-of-class online video-clips with visual, practical application (i.e. lithium and non-lithium induced tremor assessment) and online discussion in CANVAS Learning Management System; 3) Start-ofclass quiz in ExamSoft, in-class team-based application questions with instructor-led discussion; 4) Out-of-class team final exam review assignment in CANVAS. Results: Qualitative themes were student engagement, flexibility, preferences, academic and nonacademic stressors, etiquette, and defining responsibility for academic success. The majority of students preferred primary literature review, video clips, followed by online CANVAS discussions. Written assignments were the least desirable. Conclusion: These experiences are useful for qualitative evaluation of teaching and learning methods.
\end{abstract}

\section{Introduction}

\section{Blended and hybrid learning}

Recent nationwide and global experiences with the coronavirus pandemic have led many institutions to transition from traditional to online learning. The traditional pedagogy involving face-to-face instruction had already evolved alongside the maturation of the Internet (Salter et al., 2014). Teachers and researchers have sought ways to accommodate a variety of learning styles (Chick, 2018). Still, some educators have not totally abandoned the prospect of returning to face-to-face instruction, but rather have explored a comfortable medium between both traditional and online learning preferences.
Blended and hybrid learning are terms often used interchangeably in describing a combination of traditional face-to-face learning and asynchronous or synchronous elearning (Watson, 2008; Graham, 2009; Graham, 2014; Hrastinski, 2019). Blended learning has become popular in higher education with health professional programmes (Childs et al., 2005; Liu, Peng, \& Zhang, 2016). Blended learning is the broader term, generally representing simply the use of at least two learning preferences (Hrastinski, 2019). Hybrid learning can be more specific, qualifying the kind of combination or intended mix of learning techniques (Hrastinski, 2019), which these days often 
combines face-to-face with online teaching. Hybrid learning methodologies involve a purposeful combination of traditional teaching techniques with advances in technology to deliver content.

Some health professional programmes have moved away from predominantly traditional classroom lectures and instead employ problem-based discussions, cases or activities with pre-class or out-of-class preparatory materials, intended to promote student engagement and problem solving (Chang, 2016). Such problem-based learning (PBL) can help facilitate the application of individualised cognitive skills, socialisation skills, and professionalism (or reveal these as growth opportunity areas). Professionalism such as class and team etiquette can facilitate student self-learning (Klausner et al., 2021). Students work on out-of-class preparatory work from primary literature analysis and in-class team based learning (TBL) activities to facilitate deep learning and retention (Mclnerney \& Fink, 2003). Educators have sought to maximise student learning beyond the limited classroom time, and may do so with hybrid learning in order to increase experiences with active learning, teamwork, learner-focused pedagogy with instructor facilitation rather than lecture (Collis, 2003; Ilgu \& Jahren, 2018).

The authors' learning model is comprised of in-classroom problem and team-based instruction blended with required, online components outside the classroom or school day that could accommodate reading and visual preferences, as well as instructor preference for facilitated group discussion and self-directed learning activities. Students had the opportunity for a combination of what Hrastinski (2019) describes as cognitive, social and teaching presence through their assigned activities and interactions. To this end, it is a hybrid with a multi'community of inquiry' (Hrastinski, 2019) framework of inclass and e-learning, supplemented with a qualitative assessment.

The study aims were to:

1) Implement multi-inquiry e-hybrid methods at a point of timing vulnerability during the term within a health professional programme

2) Describe instructor and student class experiences and perspectives with the hybrid methodology

3) Explore emergent themes for instructional design and factors to consider when introducing new teaching methods

The overall goal was to utilise the qualitative evaluation of class experience with the assessment of the student feedback and performance to inform future course planning, instruction design, and teaching methodologies.

\section{Methods}

The authors' study used a mixed-methods approach with a qualitative observational case study of 53 students to observe class experiences with the use of hybrid learning. Institutional Review Board (IRB) approval was granted to conduct the study. The qualitative case methodology was useful for the authors' purposes in order to gather rich, exploratory data. Qualitative research would aid the understanding of instructor and student views and experiences, how meaning is developed from such experiences as well as phenomena (Ravitch, 2016); such as student performance vulnerability towards the end of the autumn term close to the end of year/winter holidays, to faculty-perceived student reluctance to in-person class attendance, or to transitioning to more self-directed learning in preparation for advanced experiential clinical rotation. Qualitative case study documents and interprets the participants' experiences and how they make sense of a phenomenon of interest (Merriam, 2009); in this instance, hybrid learning of one component of the teamtaught clinical pharmacokinetics course for third year professional students (P3) in a Doctor of Pharmacy (Pharm.D.) programme. It was taught in four lecture hours over a two week period and included in the comprehensive final examination at the end of the 16 week course period just preceding the winter break; this is a time when students' apparent anxiety and class absences are known by faculty to be very high. In preceding years, it had been taught with four lecture or problem-based (individual and/or team) learning (PBL) hours at different points during the same term. This module was selected because of the time vulnerability in the autumn term when it's taught, and the course's significance in its potential for applications to future clinical skill competencies, such as determining appropriate dosing of medications with narrow therapeutic index, adverse event monitoring and prevention.

An illustration of the e-hybrid learning methodology is depicted in Figure 1. The hybrid content delivery included:

1) Pre-class assigned reading from the required course text and two primary literature resources with targeted study questions

2) Online video-clips showing one lithium-related and one non-lithium related pharmacokinetics-based adverse effect (tremor) for students to view, an 


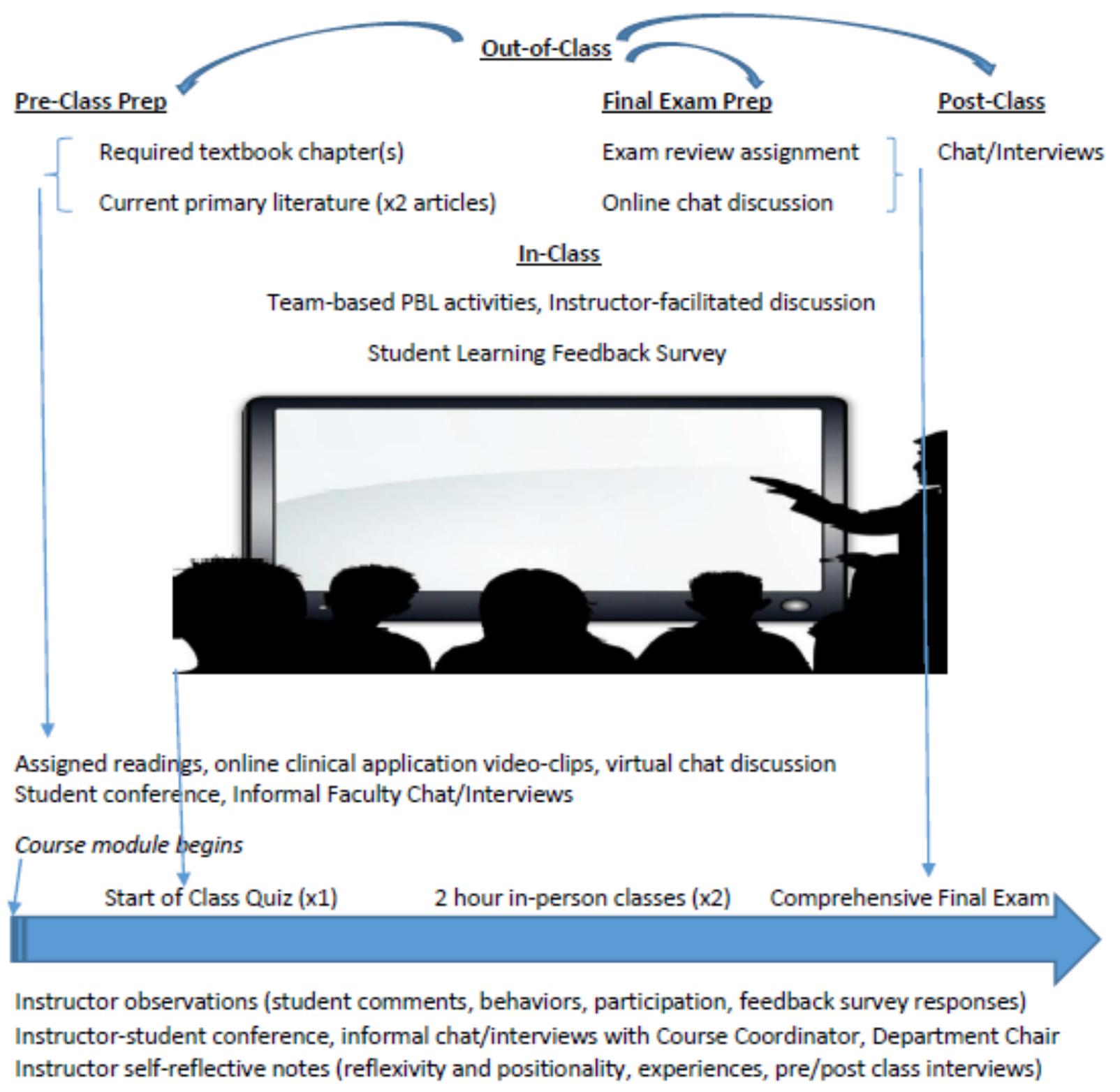

Figure 1: Multi-inquiry hybrid e-learning methods

assessment and an online discussion in the CANVAS online learning system

3) Start of class quiz via ExamSoft based on pre-class assignments, with team-based applications and instructor-led discussion in class; ExamSoft is an electronic assessment platform used for testing learners in a secure environment and utilised by multiple higher education institutions

4) Outside-class team exam review assignments and discussions in CANVAS

One of the authors was both an instructor and investigator for data collection, and made observational notes on course experiences, as well as self-reflective notes on reflexivity and positionality. Reflexivity and positionality encompass an investigator's position, background and the lens with which they interpret the study problem, methodology and findings (Malterud, 2001).

Notes were documented from pre-class preparation to post-class conclusion (see Table I), such as student attendance and participation in class and overall activities, student comments, behaviours, responses and survey or oral feedback to instructor and course coordinator. Students were given at the end of the second in-person class a brief ten minute feedback survey with open-ended 
Table I: Learning and instruction experiences qualitative data summary

\begin{tabular}{ll}
\hline Title & Description \\
\hline Codes & Active learning, adult learner, attendance, \\
& congruence, courtesy, curriculum, cultural \\
& competence, engagement, ethics, facilitator vs \\
& lecturer, flexibility, incentives, learning \\
& preferences, online discussion, participation, \\
& perceptions, professionalism, receptiveness, \\
& resistance, self-directed learning, self-initiated, \\
& stress, syllabus, teaching preferences, technology, \\
& teaching philosophy, time-management.
\end{tabular}

Themes Reception to hybrid learning preferences varies with perceptions; Multi-inquiry hybrid model yields student growth opportunities and areas for course evaluation; Engagement, Flexibility, Preferences, Academic/Non-Academic Factors, Etiquette

Student quotes

'This activity is very helpful because I have to look up the information'

'Great articles, easy to read'

'It made it easy to know what I needed to get done'

'A lot of us are just used to being spoon-fed'

'Go ask what other professors in this course have done'

'I already know what's in the textbook!'

'It helps to see the other responses to your questions in the online chat'

Student-Instructor One student conveyed surprise and/or reluctance conference;

Student comments to Faculty; Instructor-Faculty chat/interviews

Investigatorinstructor's reflexivity and positionality

Student absences and resistance to self-directed by some class members to shift completely from traditional lecture. The scope of information to cover was described as 'Too broad'. The instructor reiterated important information in the reading, activities to focus on and points associated with the online discussion posting. Some expressed a desire to disregard active learning activity and rely more or solely on direct written notes, especially for the end of term exams. The investigator shared this with the Department Chair during instructor/ faculty informal chats/interviews. learning were common based on faculty chats/ interviews.

Investigator is an experienced instructor in rank, Gen $X$ and a Digital Immigrant. Training and experience have shaped a philosophy of emphasis on active learning, PBL, TBL, class facilitation over lecture, and student initiative in learning.

Course evaluation typically comprises of quantitative assessment scores and student evaluation; qualitative data, instructor feedback, or other factors (socialisation, professionalism, culture, mental health, etc.) was formally absent in department policy, yet considered relevant to this scenario.

Investigator is of minority ethnicity and religious affiliation at the institution; only person of colour and their denomination in their Department Investigator noted student growth opportunities in cultural sensitivity, etiquette, and professionalism. questions to help identify activities they found most helpful. Feedback on prior and other course experiences for purposes of context and in relation to the current methodology were obtained by informal chats and/or brief, semi-structured interviews with: the course coordinator, a prior class instructor, an instructor utilising CANVAS online discussion boards in another course, and other investigator observations. Subsequently, cycles of preliminary open and focused qualitative coding were conducted for thematic analyses.

\section{Results}

Included in the student feedback survey was a self-rating scale of learning activities considered most helpful. Of the 53 class participants, 50 responded with their feedback. Table I summarises qualitative data collected from student and instructor teaching and learning experiences and lists the code words collected and analysed by the investigators. Table I also includes reflexivity and positionality. A code is a word or short phrase that assigns an attribute, idea, quality or meaning to a portion of qualitative data (Ravitch \& Carl, 2016). Codes are typically organised into common categories of shared attributes, similarities or meaning, from which interpretive analysis should yield one or more themes pertaining to the phenomenon being studied (Ravitch \& Carl, 2016). Codes from this study, as listed in Table I, generally pertained to student engagement with the hybrid learning model and associated factors, such as perceptions and comfort with self-directed over traditional lectures, instructor motivation and student accountability as adult learners where class attendance is not enforced, student management of time and stress, latitude within the syllabus for technology applications or piloting innovations, as well as communication, cultural perceptions and competency skills. The faculty chats/ interviews conducted by the instructor yielded information such as anticipation of heightened anxiety and absences at the time of year of the module, the allowance for absences through an adult learner policy who can take greater personal responsibility, and instances of reported resistance to self-directed learning activities, and previous exposure to CANVAS online chat discussions.

The interpretative theme was in regards to the decision to accept the hybrid model, which appeared to depend on student perceptions on what is student versus instructor responsibility for learning; some students leaned more towards initiative and self-direction while others more 
towards instructor direction. Students appreciated the assigned primary literature articles to read and the videoclip assessment of tremor. One student did mention greater familiarity with traditional lecture, while another wanted only written study notes that could be accessed in or outside class. Investigator reflexivity, positionality and experiences raised considerations of the classroom interpersonal, professionalism, and cultural factors. Examples are instances of class absences, activity nonparticipation, and communication issues. The module instructor was the only faculty member of colour in the department, and of different religious affiliation from the majority ethnicity and religious affiliation for the students and institution. The instructor was also Gen $X$ with preference for facilitated class discussions, PBL active learning, and written literature review assignments, over in-class technology-based lectures. The instructor teaching philosophy was that of student self-initiated and teambased activities in preparation and as a part of advanced experiential education in order to make competent patient care decisions as a future health professional.

The activities that were perceived as most helpful are represented in Figure 2, with the percentage of the total class favouring a particular activity. The primary literature articles were perceived by the largest majority of the class to be helpful, followed by the online video-clips of patient tremors, and then the online CANVAS discussion had the smallest proportion. Both the individual and team written assignments were found to be the least desired activities, and had the least student engagement by the instructor. There were $42.0 \%$ of responders with a preference for either individual or team assignments; $11 / 50$ (22.0\%) individual and $10 / 50(20.0 \%)$ team assignments respectively. Several of those who generally valued all course activities as helpful were also those who performed higher academically. In contrast, the majority of those who reported that they found nothing helpful generally speaking were those with lower class attendance, participation and/or performance.

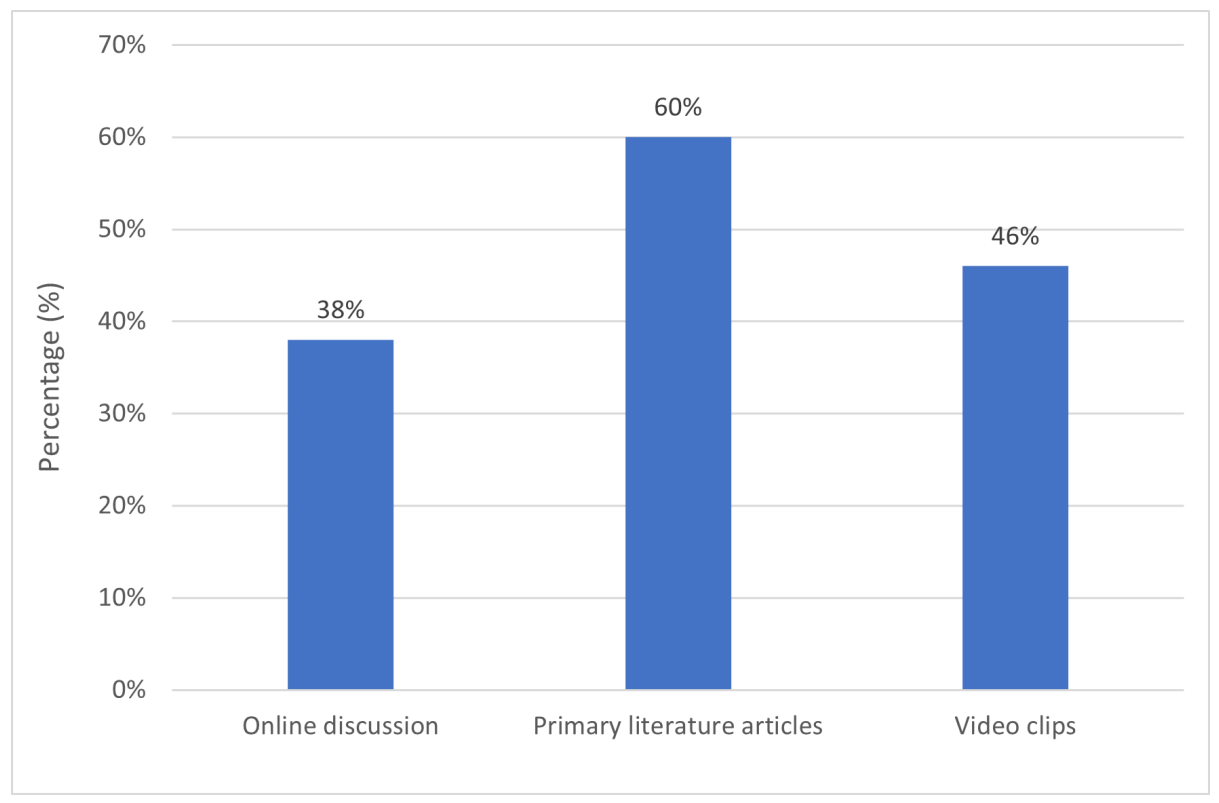

Figure 2: Learning technique

\section{Discussion}

The multi-inquiry hybrid e-learning approach described in this study, conveyed content on pharmacokinetics and its clinical application, explored student learning preferences, professionalism, and interpersonal skill development. The authors' previous work with hybrid elearning noted student benefit in capacity for class engagement and critical thinking, although mixed findings with assessment, warranting further study
(Weaver et al., 2013). Critical thinking in this setting could be described as a process of skilful analysis, assessment, self-initiated or directed, creative problemsolving as an applied competency for effective health care delivery. The authors' multiple-inquiry approach was intended to provide opportunities with applications of knowledge-base to discussions, written individual and team assignments, and practical patient assessment scenarios. The authors chose a mixed method approach with qualitative observational case study that could 
supplement usual quantitative assessments such as class quiz, pre-assigned class reading and participation scores. The additional rich qualitative data would help to utilise instructor and student experiences, perceptions and attributed meanings to explore other factors to consider when introducing new teaching methods.

Several studies report utility with blended or hybrid learning, and positive impact on student learning (Novak et al., 1999; Zapantis et al., 2008; Congdon et al., 2009; Crouch, 2009; Leonard et al., 2012). Crouch's work (2009) revealed that blended learning was instrumental in improving student preparation prior to attending class and long term knowledge retention. Congdon and colleagues (2009) compared the content delivery between a satellite programme and a traditional programme and found that academic performance and stress levels were similar in both groups with higher trends of additional viewing of lecture time seen in the satellite group and increased attendance of class by the traditional programme. In the study described here, a higher stress level may also have been a factor due to shifting the course topic from earlier in the semester to the final classes immediately prior to the end of semester comprehensive examinations, known to be a time of poor class attendance. Time and stress management are student experiences to be considered and monitored in relation to performance (Congdon, 2009). Flexibility of the hybrid approach could help to overcome high absence levels with out-of-class learning opportunities.

Some negative student attitudes have been reported towards the online component of hybrid coursework, due to students' perceived extra time demands by instructors (Leonard et al., 2012). In the authors' study where online activities were deemed as not helpful in the feedback, the reason was not given. One student commented that a heads up of this innovation was not indicated in the syllabus, and so the sudden change may have been an unwelcome surprise to some at an already stressful time of the academic year. Another study compared pharmacokinetics via a traditional classroom versus interactive, asynchronous video conferencing assessed that student satisfaction was higher with the distance learning group and higher mean student scores slightly favoured the traditional classroom group (Kidd \& Stamatakis, 2006). Wade and colleagues (1999) evaluated student performance in an advanced pharmacokinetic course using three instructional methodologies over a three year period; face to face instruction in the first year, hybrid combination of face to face and e-learning in the second year and $100 \%$ e-learning instruction in the third year (Wade et al., 1999). The results showed no difference in student performance or instructor evaluation among the three modalities (Wade et al., 1999). In the authors study, only $38.0 \%$ of the students preferred the online discussion compared to $60.0 \%$ who preferred the primary literature articles.

It generally appears that results with the blended or hybrid model vary with student preferences, as was the case with this study. A hybrid model with TBL could improve student comprehension, long term retention, medical literature evaluation, as well as communication, critical thinking skills and attitudes over the course (Zapatis, 2008; Ofstad, \& Brunner, 2013). The authors' hybrid methodology included PBL and TBL with the hope to:

1) Enhance student engagement and learning capacity

2) Accommodate flexibility for varied, multigenerational learners and instructors, time management and well-being without compromise in content delivery or undue burden

3) Reveal opportunities for student development and growth, including personal accountability for learning

Teaching methods should also bridge generation gaps in content delivery (Robey-Graham, 2008; Shatto, 2017; Swanzen, 2018). It has been proposed that it is important to perform SWOT analysis based on various aspects of the teaching environment which could potentially benefit the Gen X/Baby Boomer instructors, not only Gen Z/Millennial learners (Litshani, 2017). In conducting a SWOT analysis for this study, the authors noted that the various activities incorporated helped with student learning while weaknesses included the timing of the student activities. Our teaching methodology allowed use of technology and classroom methods that could accommodate both multigenerational students and instructors, based on the instructor's observation.

\section{Themes - Hybrid learning design factors}

\section{Student engagement}

Student engagement may be heavily influenced by what is perceived as 'teaching'. Past reliance on traditional lectures may influence receptiveness to hybrid models, including active learning activities. How do students perceive, react or respond, and evaluate new techniques, even new faculty under stress? Past course instructors described some student resistance to self-initiated active learning activities. Still, the authors introduction to hybrid methods with multi-inquiry allowed for student 
engagement through varied learning preferences and applied clinical skill preparedness. In-depth introduction, explanations, and references to student learning responsibility in course syllabi may facilitate student receptiveness.

Distractibility can interfere with student engagement and can result from concurrent course pressures; students come to class and attempt to work on outside coursework or studying, especially during class times close to midterm or final exams; in this case it was also a well-recognised cause for class absences. Today's college students have been described as spending $20.0 \%$ of classroom time on non-class activity with digital devices (Reed, 2016); and phones and computers in classrooms as distracting (McNamee, 2019). Students had been observed occasionally distracted with social media during other inclass teaching evaluations. Hybrid methodologies could help with in-class and out-of-class directed PBL activities.

\section{Flexibility}

Flexibility can be enhanced with online discussion (i.e. time-flexibility or time-burden), as well as teachinglearning mode. The primary literature articles offered some student and faculty flexibility in teaching-learning mode by providing current scholarly information in place of a formal lecture which students could review on their own; although preferences for reading outside scheduled class time may be varied. Asynchronous mini-lecture content could be provided on the online learning management system such as CANVAS to help facilitate student understanding of the primary literature; alternatively, follow-up questions could be addressed during class time. A smaller proportion of the class did not find the online discussion helpful, probably because it was the activity with which they were least familiar with, and could in turn help explain poorer student performance due to limited participation. Some graduate programmes are reluctant to impose strict attendance policies on adult learners; the hybrid methodology may afford solutions in its flexibility, while raising considerations of student growth opportunities such as interpersonal skills, and accountability in cases of noncompliance with class activities.

\section{Hybrid activity preferences}

Students expressed the greatest preference for the primary articles and video-clip, and less enthusiasm for team assignments. Faculty-selected teams were voiced by students as being less preferable to those that are individually-selected. Written assignment engagement was enhanced with incentive points for assignment completion and attendance, yet student feedback still revealed it as the less desirable activity. A few students, rather than working through the problems, tried to just ask the instructor or wait for the answers. The course coordinator suggested a future, one-hour didactic lecture and a one-hour self-directed individual and team activity within the hybrid model for a less steep learning curve. Generally speaking, instead of a complete replacement of traditional lectures with different PBL strategies some CTL leaders suggest interactive lecture or mini-lecture to precede the team learning (Brookfield, 2017). The online discussion can be burdensome for the instructor who has to facilitate the chat over hours; yet flexible, asynchronous mini-lectures might be more workable with online facilitation available during a fixed block of time. Gaining student perspectives on out-of-class time flexibility and what would best accommodate their needs would also be important. Finally, the transition over two or more professional years could mirror Wade's (1999) successful implementation.

\section{Academic and non-academic factors}

Attendance was not mandatory, but extra credit points for attendance could be earned from the course coordinator; although attendance did not necessarily guarantee engagement. At the close of the semester near examinations, student absences and anxiety levels were higher, and frustration was expressed over the replacement of 'spoon-feeding' as one student described it, with more self-directed activity and hybrid technologies. Student stressors external to the classroom were also identified. Instructor-investigator reflexivity (Table I) may offer helpful information on additional factors. Student cultural competency assessment was unavailable, although instructor experiences were noted. Introduction of instructor's cultural experiences and expressing commitment to understanding student life experiences, may be useful to facilitate class cultural responsiveness and rapport (Gray, 2012). Discussing behaviours that could be construed as inappropriate or insensitive could be beneficial, particularly where instructors are different from the predominant student population in ethnicity or otherwise. Institutional and departmental mental health policy could also be valuable in helping students and faculty navigate existing supportive resources during a stressful academic term. Establishing a set of class and exam 'etiquette' rules and reminders could raise student awareness and skills in professionalism. Adherence with course or activity instruction may in itself be an interpersonal skill of attitude, perseverance or 'grit', and 
could also be influenced by external circumstances or internal perceptions.

Increasingly, health professionals, students and educators encounter teaching and learning opportunities beyond the classroom, with more content delivered online. (Malone, Glynn \& Stohs, 2004; Driesen et al., 2007; Cain \& Fox, 2009; Falcione et al., 2011; Monaghan et al., 2011). Hybrid learning methodologies have reportedly performed modestly better than pure face-to-face or online formats (Means et al., 2010); while some hybrid studies, including teaching pharmacokinetics for instance, have reported mixed results (Wade et al., 1999; Kidd, \& Stamatakis, 2006); suggesting perhaps some benefit in exploring a wider scope of assessment factors to promote and evaluate performance. Class timing, student stressors and work-life balance; student responses to new modalities; academic policies for managing stressful points in the academic year; adult learner accommodations, cultural factors, and professionalism may add context in the evaluation, interpretation or precision of student success. Factors such as these could be weighed along with quantitative assessment scores in teaching and learning evaluation, as well as in defining student responsibility for academic success.

\section{Conclusion}

Preparing for health professional careers requires the capacity to translate and apply foundational knowledge from scientific as well as a variety of other sources. Efforts are continuously made to find more efficient ways to deliver the basics and complex concepts from an everincreasing body of information. A multi-inquiry hybrid elearning approach was introduced as a teaching innovation for clinical pharmacokinetics, with a goal to gain a rich glimpse of some experiences with students' receptiveness, learning preferences, class behaviours, and instructor observations. Emergent themes include student engagement, flexibility, learning activity preferences, academic/non-academic factors such as cultural and professionalism, and instructor/institution-learner congruence in defining student responsibility for academic success.

Evaluating the authors' hybrid model with lecture incorporation, step-wise student re-orientation to selfdirected learning, as well as incorporating growth opportunities such as determining cultural factors would be a part of next steps. While hybrid e-learning methodologies can facilitate class engagement and critical thinking, other factors must also be taken into consideration to optimise student learning, irrespective of the course content.

\section{Competing interests}

The authors declare no competing interests.

\section{Acknowledgements}

The contributions of student investigator Esomchi Umezurike, Nursing/Pre-Med student are acknowledged.

\section{References}

Brookfield, S.D. (2017). Becoming a critically reflective teacher. John Wiley \& Sons

Cain, J., \& Fox, B.I. (2009). Web 2.0 and pharmacy education. American Journal of Pharmacy Education, 73(7), Article 120

Chang, B.J. (2016). Problem-based learning in medical school: A student's perspective. Annals of Medicine and Surgery, 12, 88-89

Chick, N. (2020). Learning styles | Center for Teaching| Vanderbilt University (online). Available from: https://cft.vanderbilt.edu/guidessub-pages/learning-styles-pre

Childs, S., Blenkinsopp, E., Hall, A., \& Walton, G. (2005). Effective elearning for health professionals and students barriers and their solutions. A systematic review of the literature-findings from the HeXL project. Health Information and Libraries Journal, 22, 20-32. https://doi.org/10.1111/j.1470-3327.2005.00614.x

Collis, B. (2003). Course redesign for blended learning: Modern optics for technical professionals. International Journal of Continuing Engineering Education and Lifelong Learning, 13, 22-38

Congdon, H.B., Nutter, D.A., Charneski, L., \& Butko, P. (2009). Impact of hybrid delivery of Education on student academic performance and the student experience. American Journal of Pharmacy Education, 73(7), Article 121

Crouch, M.A. (2009). An advanced cardiovascular pharmacotherapy course blending online and face-to-face instruction. American Journal of Pharmacy Education. 73(3), Article 51

Driesen, A., Verbeke, K., Simoens, S., \& Laekeman, G. (2007). International trends in lifelong learning for pharmacists. American Journal of Pharmacy Education. 71(3), Article 52

Falcione, B.A., Joyner, P.U., Blouin, R.A., Mumper, R.J., Burcher, K., \& Unterwagner, W. (2011). New directions in pharmacy education. Journal of American Pharmacy Association. 51(6), 678-679

Gray, S. (2012). The National Equity Project. 5 ways to create a culturally responsive classroom (online). Available from: https:// blog.nationalequityproject.org/2012/08/22/5-ways-to-create-aculturally-responsive-classroom/ 
Graham, C.R. (2009). Blended learning models. In Encyclopedia of Information Science and Technology (Second Edition ed., pp. 375382): IGI Global

Graham, C.R., Henrie, C.R., \& Gibbons, A.S. (2014). Developing models and theory for blended learning research. Blended Learning: Research Perspectives, 2, 13-33

Hrastinski, S. (2019). What do we mean by Blended Learning?. TechTrends, 63, 564-569. https://doi.org/10.1007/ s11528-019-00375-5

Ilgu, A.K, \& Jahren, C.T. (2018). Faculty perspectives on benefits and challenges of hybrid learning. ASEE, June, Seattle, WA

Kidd, R.S, \& Stamatakis, M.K. (2006). Comparison of students' performance in and satisfaction with a clinical pharmacokinetics course delivered live and by interactive videoconferencing. American Journal of Pharmacy Education. 70(1), Article 6

Klausner, E.A., Pitchford, K.D., Schmidhammer, J.L., \& Phillips, B.R. (2021). Pharmacy, Nursing, and physician assistant studies student self-report and perceptions regarding classroom etiquette. Pharmacy Education 21(1), 194-202

Leonard, S.N., Murphy, K., Zaeem, M., \& DiVall, M.V. (2012). An Introductory Review Module for an Anti-Infectives Therapeutics Course. American Journal of Pharmacy Education. 76(7), Article 135

Litshani, N. F. (2017). Positioning and realigning the role of the teacher for classroom practice. In M. D. Magano, S. J. Mohapi, \& D. Robinson (Eds), Realigning teacher training in the 21st century. Andover, United Kingdom: Cengage Learning EMEA

Liu, Q., Peng, W., Zhang, F., Hu, R., Li, Y., \& Yan, W. (2016). The Effectiveness of Blended Learning in Health Professions: Systematic Review and Meta-Analysis. Journal of medical Internet research, 18(1), https://doi.org/10.2196/jmir.4807

Malone, P.M., Glynn, G.E., \& Stohs, S.J. (2004). The development and structure of a web-based entry-level doctor of pharmacy pathway at Creighton University Medical Center. American Journal of Pharmacy Education. 68(2), Article 46

Malterud, K. (2001). Qualitative research: Standards, challenges and guidelines. The Lancet. 358, 483-488

Mclnerney, M.J., \& Fink, L.D. (2003). Team-based learning enhances long-term retention and critical thinking in an undergraduate microbial physiology course. Microbiology Education. 4, 3-12

McNamee, R. (2019). I mentored Mark Zuckerberg. I loved Facebook. But I can't stay silent about what's happening. Time, 193(3). Available from: https://time.com/magazine/us/5505429/ january-28th-2019-vol-193-no-3-u-s/

Means, B., Toyama, Y., Murphy, R., Bakia, M. \& Jones, K. (2010). Evaluation of evidence-based practices in online learning: A metaanalysis and review of online learning studies. Washington DC: US Department of Education, Office of Planning, Evaluation, and Policy Development

Merriam, S.B. (2009). Qualitative research: A guide to design and implementation. San Francisco, CA: Jossey-Bass
Monaghan, M.S., Cain, J.J., Malone, P.M.. (2011). Educational technology use among US colleges and schools of pharmacy. American Journal of Pharmacy Education, 75(5), Article 87

Novak, G.M., Patterson, E.T., Gavrin, A.D., \& Christian, W. (1999). JustIn-Time Teaching: Blending Active Learning with Web Technology. New York, NY: Prentice Hall

Ofstad, W., \& Brunner, L.J. (2013). Team-based learning in pharmacy education. American Journal of Pharmacy Education. 77(4), Article 70

Ravitch, S.M. \& Carl, N.M. (2016). Qualitative research: Bridging the conceptual, theoretical and methodological. Thousand Oaks, CA: Sage Publications

Reed, L. (2016). Digital distraction is on the rise (online). ScienceDaily. Available from: www.sciencedaily.com/releases/ 2016/01/160115140535.html

Robey-Graham, V.A. (2008). Teaching multi-generational students: A case study of community college classrooms. Arizona State University, Arizona, United States

Rogers, E.M. (1983). Diffusion of Innovations. New York: Macmillan Publishing

Salter, S.M., Karia, A., Sanfilippo, F.M., \& Clifford, R. (2014). Effectiveness of E-Learning in Pharmacy Education. American Journal of Pharmacy Education, 78(4), Article 83

Shatto, B., \& Erwin, K. (2017). Teaching Millennials and Generation Z: Bridging the generational divide. Creative Nursing, 23(1), 24-28

Swanzen, R. (2018). Facing the generational chasm: The parenting and teaching of generations $Y$ and $Z$. International Journal of Child, Youth and Family Studies, 9(2), 125-150

Watson, J. (2008). Blended learning: The convergence of online and face-to-face education. Promising Practices in Online Learning. North American Council for Online Learning

Wade, W.E., Cobb, H.H., Spruill, W.J., \& Chisholm, M.A. (1999). Assessment of student performance in an advanced pharmacokinetics course taught by three methods of instructional delivery. American Journal of Pharmacy Education. 63, 82-5

Weaver, S.B., Oji, V.U., Etienne, E., Stolpe, S.F. \& Maneno, M.K. (2013). Hybrid e-learning approach to health policy. Currents in Pharmacy Teaching and Learning. https://doi.org/10.1016/j.cptl.2013.11.013

Zapantis, A., Machado, C., Nemire, R., \& Leung, S. (2008). An elective course in adult acute care medicine using a hybrid delivery system. American Journal of Pharmacy Education. 72(5), Article 105 